\title{
アルコキシシラン添加チーグラーーナッタ触媒で得られた ポリプロピレンの非対称マルコフ過程による解析
}

\author{
中條利一郎*1 ・坂口 英史*1 $・$ Mika HÄRKÖNEN*2 $・$ Jukka V. SEPPÄLÄ*2
}

(受付 1994 年 5 月 6 日・審査終了 1994 年 7 月 11 日)

\begin{abstract}
要 旨 重合が非対称マルコフ過程に従う場合の条件つき確深を NMR 三連子強度から求める式を導き,これを アルコキシシラン添加チーグラーーナッタ触媒で得られたポリプロピレンに適用した。 未分別試料，熱へプタン不 容分ともに, 対称中心から (fluctuate している) 非対称中心への転換に際し，一方 ( $L$ とする) の中心の転換に比一 て、D中心への転換は生じていないか, 生じていても生じ方が少ないこと，外部ドナ一の濃度に伴うインタクチシ チーの単調增加は $p_{\mathrm{LL}}$ が大きくなるためであること, 芳香族系のドナーの方がインタクチシチーの向上に有勃であ ること,および外部ドナーの添加によるイソタクチシチーの向上は $L$ 中心, $D$ 中心の両方がプラスに作用している のではなく，前者による向上が後者による低下を淩駕していることによることを明らかにした。
\end{abstract}

\section{1 はじめに}

プロペンの重合機構としては多くの重合系に対して二 中心モデル"が第一近似として受け入れられている゙．す なわち，触媒には 2 種類の活性中心があり，一方は $D$ と $L$ の選択を Bernoulli 的に行う非対称 Bernoulli 中心, 他 方は $m$ と $r$ の選択を Bernoulli 的に行う対称 Bernoulli 中心で, 得られたポリマーはこれら 2 種類の活性中心か ら得られたものの混合物とするモデルである。このモデ ルの定量化は ${ }^{13} \mathrm{C}$ 溶液 NMRのメチル基のピークの強度 を用いて行われる。このため, 强度の精度, 独立変数の 数の制限の範囲内で最適のモデルといえょう.しかし， 重合機構の解析という観点からは不十分なのも事実で, いくつかの修飾が行われている。 その一つが三中心モデ ルで，その中でも 2 種類の非対称 Bernoulli 中心と 1 種 類の対称 Bernoulli 中心からなるとするものが多用され

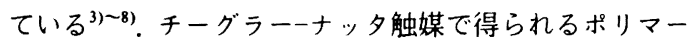
の立体規則性向上のため, 適当な Lewis 塩基をドナーと して用いた時, 対称中心の一部が非対称中心に変わる. これはもとからあった非対称中心ほど rigid でなく，D 中心と $L$ 中心の間でゆらぐ．このため,この中心により 得られた部分が対称中心により得られたものとして分別 される可能性がある9”。このゆらぎは触媒の一方の中心 から他方への switch と呼ばれる”．このようにして得ら れたポリマーのタクチシチーには chronotacticity という 魅力的な名前がつけられている(1). また，このような活

*1 西東京科学大学理工学部（画409-01 山梨県北都留郡上野原 町八ッ沢 2525)

*2 Department of Chemical Engineering, Helsinki University of Technology (Kemistintie 1, Espoo, Finland FIN-02150)

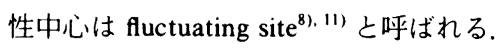

この論文で取り扱う $\mathrm{MgCl}_{2} / \mathrm{TiCl}_{4} /$ ジインブチルフ夕 ラート-AlEt / $_{3}$ 外部ドナー系(2)も fluctuating siteになる系 である゙1".この論文では、このような系を別の観点から 解析し, 重合機構についてのより正確な情報を得ること を目的とする。

Fluctuating siteにより，DポリマーとLポリマーとの ブロックポリマーが得られるのであれば，そこにはマル コフ的特徵がみられるはずである. 重合温度, $T$ で得ら れるポリマーの非対称マルコフ過程を検証する式として

$$
\Delta \varepsilon_{\mathrm{A}}=-k T \ln \{1-4 /[(m r)+2(r r)]+1 /(r r)\}
$$
が著者の一人 (RC)により与えられている ${ }^{13)}$.この式そ のものは正しいが，現実の非対称過程により得られたポ リマーへの適用に際しては, 分母に現れる三連子分率, $(m r)$ も $(r r)$ あ共に 1 に比べて小さいため, 実測値のわ ずかな絶対誤差が結果に重大な影響を及ぼす。したがっ て, 非対称マルコフ過程に従うことを作業仮説に選ぶの であれば， $x$ の後に $y$ が現れる条件つき確率， $p_{x y}(x, y=$ $D, L)$ を用いればよい. 次章では条件つき確率を NMR データから求める式を導く。その際，レベルとしては (1) 式と同じにする.すなわち, NMR デー夕は三連子分 率を用い，かつ全部の部分が非対称過程により得られた あのとする，マルコフ過程であれば，三連子以上の情報 は不要だからである. また, 後者の仮定は二中心モデル より後退している.これはパラメーターの数か增えるこ とによる曖昧さを排除するためである。したがって,こ の論文での取り扱いは Markov vs. Bernoulli では二中心 モデルより優れており，対称過程により得られた部分の 考慮の有無に関しては二中心モデルの方が優れている. 第 3 章では, 標題の $\mathrm{MgCl}_{2} / \mathrm{TiCl}_{4}$ /ジィソブチルフタラー 
ト- $\mathrm{AlEt}_{3} /$ 外部ドナー系の NMR のデー夕に第 2 章で求 めた式を適用し，解析を行う。用いるデー夕は著者のう ち, 二人 (MH, JVS) らが求めたものである. 結論を一部 先走りすると，この論文で展開する手法が最も有効と思 われるのは熱へプタン可溶分であると思われるが，これ に対しては成功しなかった，その理由は本文で述べると して, 未分別試料, 熱へプタン不溶分に適用した結果か らは有用な結論が得られたので, 報告することにする. 第 4 章では電子密度と第 3 章で求めた確率パラメーター との相関を求める. 前報(4)で MOPAC を用いて MNDO 法により求めた $O$ 電子の電子密度と二中心モデルの確 率パラメーター $\alpha$ との間に相関を見いだしている。 む し、二中心モデルが十分なモデルであれば, 外部ドナー の添加により增加するのは $\omega$ だから, 電子密度は $\alpha て ゙$ はなく $\omega$ との間に相関がみられるはずである. そこで, 非対称マルコフモデルの採用により, 電子密度と確率パ ラメーターとの間に相関がみられるかどうかをみるのが 第 4 章の目的である.

\section{2 理論}

前章での議論に基づきここでは $p_{\mathrm{DL}}$ その他の条件つ き確率を三連子分率 $(m r)$ などの関数として表す式を求 める. 三連子分率は

$$
\begin{aligned}
(m m) & =p_{\mathrm{D}} p_{\mathrm{DD}}{ }^{2}+p_{\mathrm{L}} p_{\mathrm{LL}}^{2} \\
& =\left(p_{\mathrm{LD}} p_{\mathrm{DD}}^{2}+p_{\mathrm{DL}} p_{\mathrm{LL}}^{2}\right) /\left(p_{\mathrm{DL}}+p_{\mathrm{LD}}\right) \\
(m r) & =p_{\mathrm{D}}\left(p_{\mathrm{DD}} p_{\mathrm{DL}}+p_{\mathrm{DL}} p_{\mathrm{LL}}\right)+p_{\mathrm{L}}\left(p_{\mathrm{LL}} p_{\mathrm{LD}}+p_{\mathrm{LD}} p_{D D}\right) \\
& =2 p_{\mathrm{DL}} p_{\mathrm{LD}}\left(p_{\mathrm{DD}}+p_{\mathrm{LL}}\right) /\left(p_{\mathrm{DL}}+p_{\mathrm{LD}}\right) \\
(r r) & =p_{\mathrm{D}} p_{\mathrm{DL}} p_{\mathrm{LD}}+p_{\mathrm{L}} p_{\mathrm{LD}} p_{\mathrm{DL}}=p_{\mathrm{DL}} p_{\mathrm{LD}}
\end{aligned}
$$

で与えられる。 ただし， $p_{\mathrm{D}}, p_{\mathrm{L}}$ は一つ手前のモノマー単 位のコンフィグレーションに無関係に $D$ または $L$ を選 ぶ確率である.これらの式から $p_{\mathrm{DL}}$ と $(m r),(r r)$ との 関係として

$$
p_{\mathrm{DI} .}{ }^{2}-\{2(r r) /[(m r)+2(r r)]\} p_{\mathrm{DL}}+(r r)=0
$$

を得る.この式は $p_{\mathrm{DL}}$ に関する二次方程式であり, 二つ の根のうち, どちらが $p_{\mathrm{DL}}$ なのか決められない，一方,

(2) 式の第二式と第三式との比較から

$$
p_{\mathrm{DL}}+p_{\mathrm{LD}}=2(r r) /[(m r)+2(r r)]
$$

となり， $p_{\mathrm{LD}}$ を求める式も(3) 式と同じであることがわ かる. そこで, 以下 (3) 式の根のうち, 大きい方を $p_{\mathrm{DL}}$, 小さい方を $p_{\mathrm{LD}}$ とすることにする，すなわち，

$$
\begin{aligned}
p_{\mathrm{DL}}= & (r r) /[(m r)+2(r r)] \\
& +\left\{\{(r r) /[(m r)+2(r r)]\}^{2}-(r r)\right\}^{1 / 2} \\
p_{\mathrm{LD}}= & (r r) /[(m r)+2(r r)] \\
& -\left\{\{(r r) /[(m r)+2(r r)]\}^{2}-(r r)\right\}^{1 / 2}
\end{aligned}
$$

となる。すちろん,

$$
\begin{aligned}
& p_{\mathrm{DD}}=1-p_{\mathrm{DL}} \\
& p_{\mathrm{LL}}=1-p_{\mathrm{LD}}
\end{aligned}
$$

である.

Table 1. Compounds used as external donors with codes and suppliers ${ }^{12}$

\begin{tabular}{lll}
\hline \multicolumn{1}{c}{ Alkoxysilane } & Code & Supplier \\
\hline Diethoxydimethylsilane & $1 \mathrm{a}$ & Petrarch \\
Diethoxymethylphenylsilane & $1 \mathrm{~b}$ & Petrarch \\
Diisopropenyloxydimethylsilane & 7 & Petrarch \\
Dimethoxydiphenylsilane & 2 & Petrarch \\
Dodecyldiethoxymethylsilane & $1 \mathrm{c}$ & Petrarch \\
Dodecyltriethoxysilane & $4 \mathrm{a}$ & Petrarch \\
Ethoxytrimethylsilane & 5 & Alfa \\
Isobutyltrimethoxysilane & $3 \mathrm{a}$ & Hüls \\
Triethoxymethylsilane & $4 \mathrm{c}$ & Alfa \\
Triethoxyphenylsilane & $4 \mathrm{~b}$ & Alfa \\
Trimethoxymethylsilane & $3 \mathrm{~b}$ & Fluka \\
Trimethoxyphenylsilane & $3 \mathrm{c}$ & Petrarch \\
Trimethoxypropylsilane & $3 \mathrm{~d}$ & Fluka \\
Tripropoxymethylsilane & 6 & Petrarch \\
\hline
\end{tabular}

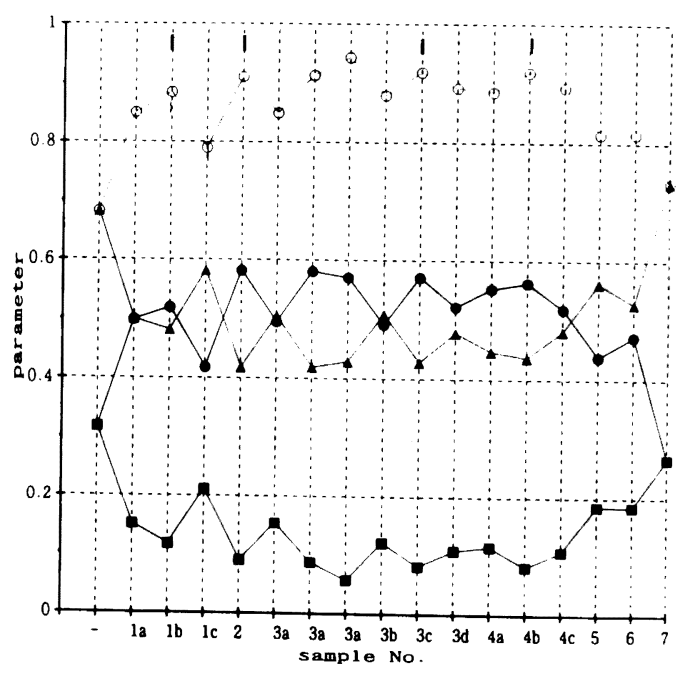

Fig. 1. Conditional probabilities in the asymmetric Markovian process vs. species of external donors for unfractionated samples.

$-\mathbf{-}, p_{\mathrm{DL}} ;-\mathbf{\square}, p_{\mathrm{LD}} ; \cdots \mathbf{\Delta} \cdot p_{\mathrm{DD}} ; \cdots \bigcirc \cdots, p_{\mathrm{LL}} ;$

I, phenyl.

\section{3 非対称マルコフ過程としての解析}

外部ドナーとして用いたアルコキシシランの名称を コード，供給先とともに Table 1に示す. Fig. 1 はこれら のアルコキシシランを用いて得られたポリプロピレンの 未分別試料の条件つき確率を(5), (6) 式により求めたも のをコードに対してプロットしたものである. 外部ド 
アルコキシシラン添加チーグラーーナッタ触媒で得られたポリプロピレンの非対称マルコフ過程による解析

ナー No. 7 (diisopropenyloxydimethylsilane) を用いた場 合を除いて, $p_{\mathrm{LL}}$ (正確には $p_{\mathrm{DD}}$ と $p_{\mathrm{LL}}$ のうち大きい方) と $p_{\mathrm{DL}}\left(p_{\mathrm{DL}} と p_{\mathrm{LD}}\right.$ のうち大きい方) が外部ドナーの添 加により大きくなっていることがわかる.これは外部ド ナーの役割について文献 11 で得た結論のうち,

2 対称中心加 (fluctuate している) 非対称中心 への転換

を

2 対称中心から (fluctuateしている) 非対称中心 への転換に際し， $L$ 中心の転換に比へてて，D中 心への転換は生じていないか, 生じていても生 じ方が少ない

とより詳しい表現に変えることができる.

図の横軸でーで示したのは外部ドナーを添加していな いものの結果である。この場合だけ（厳密には No.7も そうだが、こちらは除いて考えることにする） $p_{\mathrm{LL}}=p_{\mathrm{DD}}$,

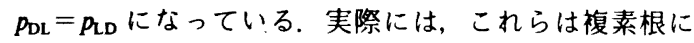
なっているが，実数部の絶対値に比べて虚数部のそれが 小さいため, 後者を無視し，（5）式の等根として求めて ある.このことから， $D$ 中心と $L$ 中心とが同数個存在す るとの暗黑の仮定が外部ドナーを添加しない場合にのみ 正しいことがわかる. 一部の論文で, 対称 Bernoulli 過程 を単に Bernoulli 過程, 非対称 Bernoulli 過程を enantiomorphic 過程と呼んでいるものがある、筆者らがそ の用語法を用いないのは確率論の用語と立体化学の用語 を対置するのがよくないとの考えによるが，上の外部ド ナーの添加により enantiomorphic site の数が等しくない という事実も enantiomorphic 過程という言い方がよく ないことを示している.

また，図中 3aが三つある.これらは，いずれも外部ド ナー3a を添加した系で, 外部ドナー/ $\mathrm{AlEt}_{3}$ が左から順 に0.05, 0.1,0.2のものである. これらの挙動から, 文献 11 の結論のうち,

4 Fluctuateしている中心により得られたポリ マーのイソタクチシチーは外部ドナーの濃度と ともに增加する

を

4 Fluctuate している中心により得られたポリ マーのインタクチシチーの外部ドナーの濃度に 伴う単調増加は $p_{\mathrm{LL}}$ が大きくなるためである と詳細化できる.

図中 phenyl と記してあるのはいずれあフェニル基を あつアルコキシシランを用いた場合である。これらの $p_{\mathrm{LL}}$ の方が脂肪族系のあののそれよりも一般的に大き い.したがって, 新たに

5 芳香族系の Lewis 塩基の方か脂肪族系のものよ りイソタクチシチーの改善に有効である

をつけ加えることができる. 外部ドナーNo. 3 の最後の

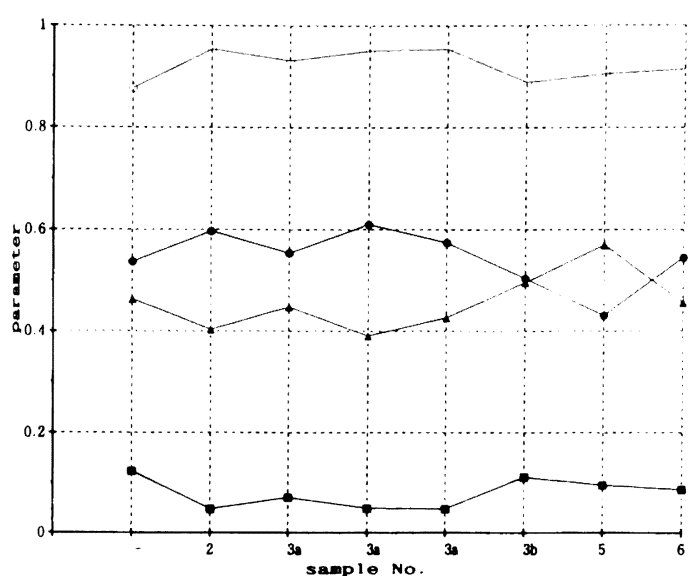

Fig. 2. Conditional probabilities in the asymmetric Markovian process vs. species of external donors for heptane-insoluble fractions.
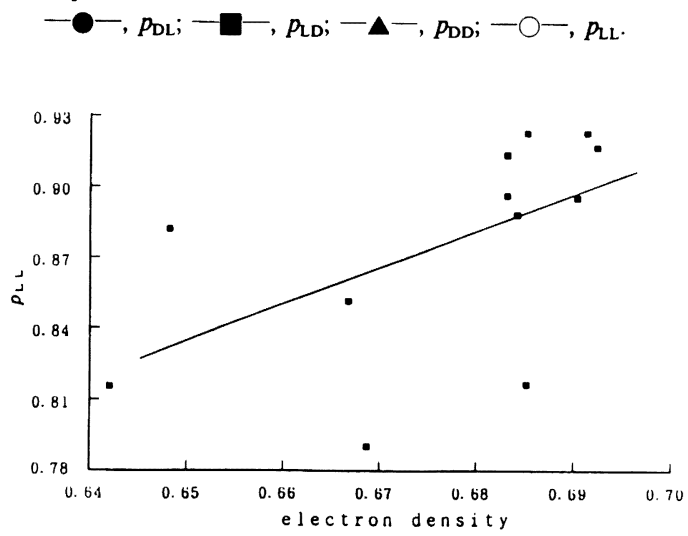

Fig. 3. Conditional probabilities, $p_{\text {LL }}$ 's, vs. electron densities for unfractionated samples.

あのは芳香族系のものより值が大きい。これは，既述の とおり, 結論 4 を導くため, 外部ドナー/ $/ \mathrm{AlEt}_{3}$ を大きく したためである. No. 3 を除いてはすべて外部ドナー/ $\mathrm{AlEt}_{3}$ を統一してある.

熱へプタン不溶分についての同様なプロットを Fig. 2 に示す，未分別試料の結果と同様の傾向がみられる。 二 中心モデルによる解析"1では分率パラメーター $\omega$ はへ プタン不溶分で增加したのに対し, 確率パラメーターは $\alpha$ ああほとんど変わらなかった。ここでの結果はこれ に対応している.

第 1 章で述べたところによれば，この論文での取扱い の効用は熱へプタン可溶分に最も顕著に現れるはずであ る.しかし，現実には (5), (6) 式により求めた条件つき 確率の值はすべて複素数になる。これは非対称マルコフ 
過程により得られたポリマーよりは対称 Bernoulli 過程 によるものの方が圧倒的に多いためであろう.

\section{4 確率パラメーターと電子密度との相関}

MOPAC を用いて MNDO 法で求めたアルコキシシラ ンの $\mathrm{O}$ 原子の電子密度 ${ }^{15)}$ 末分別試料の $p_{\mathrm{LL}}$ に対してプ ロットしたのが Fig. 3 である. 相関は必ずしもよくない (したがって相関係数は求めない) が, 正の相関がみられ る. $p_{\mathrm{DL}}$ にもほぼ同程度の正の相関がみられる。した がって, あらたに結論 6 として,

6 アルコキシシランの添加によるインタクチシ チーの向上は， $L$ 中心， $D$ 中心の両方がプラス に作用しているのではなく，前者による改善が 後者による低下を淩駕していることによる をつけ加えることができる。

\section{5 結 論}

プロペンのチーグラーーナッ夕触媒による重合におけ るアルコキシシランの添加の影響を非対称マルコフ過程 による解析の結果, 前報の結論 2,4 を詳細化することが できた. また，アルコキシシランの $\mathrm{O}$ 原子の電子密度之 の比較からあらたに結論 5 をつけ加えることができた。 全部を列挙すると

1 対称中心の選択的被毒

2 対称中心から (fluctuateしている) 非対称中心 への転換に際し， $L$ 中心の転換に比べて， $D$ 中 心への転換は生じていないか, 生じていても生 じ方が少ない

3 全体としてのイソタクチシチーの増加は fluctuate している中心から得られたポリマーの増加 による

4 Fluctuateしている中心により得られたポリ マーのイソタクチシチーの外部ドナーの濃度に 伴う単調増加は $p_{\mathrm{LL}}$ が大きくなるためである
5 芳香族系の Lewis 塩基の方が脂肪族系のものよ りイソタクチシチーの改善に有効である

6 アルコキシシランの添加によるイソタクチシ チーの改善は, $L$ 中心, $D$ 中心の両方がプラス に作用しているのではなく，前者による向上が 後者による低下を凌駕していることによる となる。

\section{文献}

1) 中條利一郎, 化学, 38, 420 (1981)

2) S. N. Zhu, X.Z. Yang, and R. Chûjô, Polym. J., 15, 859 (1983).

3) H. N. Cheng, J. Appl. Polym. Sci., 35, 1639 (1988).

4) H. N. Cheng, G. N. Babu, R. A. Newmark, and J. C. W. Cheng, Macromolecules, 25, 6980 (1992).

5) H. N. Cheng, Makromol. Chem., Theory Simul., 1, 415 (1992).

6) M. W. van der Burg, J. C. Chadwick, O. Sudmeijer, and H. J. A. F. Tulleken, Makromol. Chem., Theory Simul., 2, 399 (1993).

7) R. Paukkeri, E. Iiskola, A. Lehtinen, and H. Salminen, Private Communication.

8) M. Härkönen, J. V. Seppälä, and H. Salminen, Private Communicaton.

9) K. Soga, T. Shiono, and Y. Doi, Makromol. Chem., 189, 1531 (1988).

10) Theyssié, S. van der Ven, "Polypropylene and Other Olefins, Polymerization and Characterization", Elsevier, Amsterdam (1990), p. 163.

11) R. Chûjô, Y. Kogure, and T. Väänânen, Polymer, 35, 339 (1994).

12) M. Härkönen, J. V. Seppälä, and T. Väänänen, Makromol. Chem., 192, 721 (1991).

13) R. Chûjô, Rep. Prog. Polym. Phys. Jpn., 11, 451 (1968).

14) M. Härkönen, J. V. Seppälä, R. Chûjö, and Y. Kogure, to be Submitted.

15) M. Harkonen, L. Kuutti, and J. V. Seppala, Makromol. Chem., 193, 1413 (1992).

\section{Asymmetric Markovian Process in the Polypropylene Obtained by Ziegler-Natta Catalyst with External Alkoxysilane Donors}

Riichirô ChOJô*1, Eiji SAKaguChI*1, Mika HäRKÖNEN*1, and Jukka V. SEPPäLÄ*2

*1 Department of Materials Engineering. The Nishi-Tokyo University (2525 Yatsuzawa, Uenohara-machi, Yamanashi, 40901 Japan)

*2 Department of Chemical Engineering, Helsinki University of Technology (Kemistintie 1. Espoo, Finland FIN-02150)

The formulae for conditional probabilities are derived with the terms of NMR triad tacticities for the polymers whose polymerization process is described by the asymmetric Markovian process. The obtained formulae are applied to the polypropylenes polymerized by Ziegler-Natta catalysts with external alkoxysilane donors. For both of unfractionated samples and heptane-insoluble fractions, the followings were clarified: 1) on the transformation from symmtric to (fluctuating) asymmetric centers the transformation of one (hereafter, $L$ ) site is much enhanced than that of $D$ site, 2) the monotonous increase of isotacticity as a result of the increase of the concentration of the donors is due to the increase of $p_{\mathrm{LL}}, 3$ ) aromatic donors are effective than aliphatic ones for the improvement of isotacticity, and 4) 
アルコキシシラン添加チーグラーーナッタ触媒で得られたポリプロピレンの非対称マルコフ過程による解析

the improvement of isotacticity after an addition of the alkoxysilanes is not due to the contribution from both of $L$ and $D$ sites, but the positive contribution from the former is larger than the negative one from the latter.

KEY WORDS Polypropylene / Asymmetric Markovian / External Alkoxysilane Donor / Triad Tacticity /

Fluctuating Site /

(Received May 6, 1994: Accepted July 11, 1944)

[Kobunshi Ronbunthu, 51(10), 647-651 (1994)] 